\title{
Growth conditions that increase or decrease lifespan in Saccharomyces cerevisiae lead to corresponding decreases or increases in rates of interstitial deletions and non-reciprocal translocations
}

Patrick H. Maxwell

\begin{abstract}
Background: Accumulation of DNA damage, mutations, and chromosomal abnormalities is associated with aging in many organisms. How directly various forms of genomic instability contribute to lifespan in different aging contexts is still under active investigation. Testing whether treatments that alter lifespan change mutation rates early during lifespan could provide support for genomic instability being at least partly responsible for changes in the rates of aging.

Results: Rates of mutations, direct repeat recombination, or retrotransposition were measured in young cell populations from two strain backgrounds of Saccharomyces cerevisiae exposed to several growth conditions that shortened or extended yeast chronological lifespan. In most cases, rates of genomic instability did not consistently increase in young cells exposed to lifespan-shortening conditions or decrease in young cells exposed to lifespan-extending conditions. The mutation rate for a copy of the CAN1 gene integrated onto the right arm of chromosome VIII did show expected increases or decreases in young cells in the lifespan-altering growth conditions. These mutations were determined to frequently result from non-allelic recombination events, including non-reciprocal translocations, and were more strongly stimulated by using hydroxyurea to induce DNA replication stress than by the general DNA-damaging agent methyl methanesulfonate.

Conclusions: The results are not consistent with changes in mutation rates in general mediating the influence of alternative growth conditions on yeast lifespan. The strong correlation between non-allelic recombination events and the effects of the alternative growth conditions on lifespan indicates that genomic instability due to changes in recombination rates may directly contribute to the rate of aging or that lifespan-altering treatments may consistently increase or decrease DNA replication stress. These results further support the connection between DNA replication stress and aging observed in multiple organisms. Chromosomal abnormalities that likely arise from recombination events are more prevalent in multiple human tissues with increasing age, and further work in yeast could help to define mechanisms responsible for this observation and the impact of chromosomal abnormalities on aging.
\end{abstract}

Keywords: Aging, Chromosomal rearrangement, Chronological lifespan, Mutation, Recombination, Retrotransposition, Saccharomyces cerevisiae

Correspondence: maxwep2@rpi.edu

Department of Biological Sciences, Rensselaer Polytechnic Institute, CBIS

Room 2123, 110 8th Street, Troy 12180, NY, USA 


\section{Background}

Frequent references are made to the contribution of DNA damage and mutations to the aging process, but a number of questions remain regarding the precise relationship between genomic instability and aging. Evidence consistent with a role for genomic instability in aging includes increases in specific forms of DNA damage, small-scale mutations, and chromosomal rearrangements with age in Saccharomyces cerevisiae, Drosophila melanogaster, rodents, and in cells from people of different ages [1-6]. The magnitude of the increase in mutations or whether mutations increase at all with age varies by tissue in mice $[2,3,7,8]$. Some DNA repair activities have been reported to be less efficient with age, such as base excision repair, homologous recombination, and non-homologous end joining in mammalian cells and tissues [6,9-14]. Changes in the activities of DNA damage signaling pathways have also been observed in aging mammalian cells $[15,16]$. Human progerias associated with symptoms of premature aging are typically caused by mutations in single genes that compromise DNA repair and replication, and mice with mutations in certain DNA repair genes have shortened lifespans [17-20]. How shortened lifespan due to inherited deficiencies in DNA repair activities relates to normal aging has been questioned [20], but increased production of the progerin protein responsible for Hutchinson-Gilford Progeria Syndrome occurs in response to telomere shortening during aging of normal human fibroblasts [21].

The influence of age on frequencies of chromosomal abnormalities in human tissue samples has been analyzed using single nucleotide polymorphism (SNP) arrays in multiple studies. Chromosomal loss of heterozygosity events in human colon crypts are more frequent in older individuals [22]. A few studies identified that mosaic chromosomal abnormalities in human blood and buccal samples are detected at frequencies of less than $0.5 \%$ in individuals under 50 years of age but at frequencies of $\sim 2-3 \%$ in individuals 75 years of age or older [23-25]. A high burden of single nucleotide variants has been observed in human neurons by sequencing genomes of individual cells (up to $\sim 1,500$ per genome), but the influence of age on accumulation of these variants remains to be determined [26].

While these and other observations are consistent with genomic instability promoting aging, one challenge is showing that improved DNA repair and decreased genomic instability directly extend lifespan. Part of the reason this is challenging is that many DNA repair activities involve numerous proteins, so overexpressing a single DNA repair gene may not improve repair [6]. Extension of lifespan in mice through dietary restriction ameliorates the age-related decrease in base excision repair [9], and extension of lifespan in yeast by inhibition of growth signaling reduces mutation accumulation during aging [27], but it is unclear whether these changes directly contribute to lifespan extension in these models. Mice with extended or shortened telomeres have corresponding increases or decreases in lifespan [28-30], and activation of telomerase in mice can delay normal aging $[31,32]$, but these studies do not address the role of other aspects of genomic instability in aging.

If genomic instability directly promotes aging, then levels of genomic instability early during lifespan should influence later accumulation of characteristics of aging and at least partly determine lifespan. Manipulations that alter lifespan would be expected to change the rate of accumulating mutations in young cells or organisms, causing them to age at different rates. Dietary restriction has been shown to increase base excision repair in young mice [9], and further examination of genomic instability early during lifespan in response to manipulations that alter lifespan could help address the role of DNA damage and mutations during aging.

Genomic instability during aging has been examined using two aging models for Saccharomyces cerevisiae. Chronological aging occurs as non-dividing cells in stationary phase lose function/viability [33], and is associated with increased small-scale mutations, chromosomal rearrangements, and mobility of retrotransposons [34, 35]. Replicative aging occurs as yeast mother cells undergo subsequent rounds of cell division [33], and is associated with increased loss of heterozygosity related to instability of the rDNA region as well as increased mobility of retrotransposons [36-39]. Mutations that inhibit double-strand break repair or that compromise DNA replication shorten yeast replicative lifespan [40, 41]. In contrast, large-scale screens for mutations that influence yeast chronological lifespan (CLS) have not identified DNA repair genes as major regulators of lifespan [42, 43]. A variety of changes to media and growth conditions have been demonstrated to alter lifespan in yeast, including increasing or decreasing the concentration of glucose, use of non-fermentable carbon sources, high medium osmolarity, and changing the growth temperature [44-48]. The current study addresses whether these conditions alter S. cerevisiae lifespan at least partly by changing rates of genomic instability in young cells. Multiple conditions that increase or decrease lifespan were tested for decreases or increases, respectively, in rates of genomic instability using multiple assays in two strain backgrounds. Overall, there was limited correspondence between these growth conditions and rates of genomic instability in young cells, with the exception of mutations at one locus that were found to predominantly result from non-allelic recombination events. These recombination events were stimulated much more by DNA replication stress than a general DNA damaging agent. This observation supports other work in yeast 
showing that DNA replication stress and genomic instability due to recombination may be particularly relevant to aging $[37,49,50]$.

\section{Methods}

\section{Yeast strains and media}

Yeast strains were grown using standard rich (YPD) or synthetic complete (SC) medium (each containing $2 \%$ glucose), as well as yeast extract-peptone (YP) medium containing high $(10 \%)$ or low $(0.2 \%)$ concentrations of glucose or YP medium containing non-fermentable carbon sources (3\% potassium acetate, $2 \%$ ethanol, or $3 \%$ glycerol) [51]. Strains harboring mutant alleles were generated by one-step gene replacement or disruption using lithium acetate transformation. Strain SCE218 was derived from JC297 in the GRF167 background (MAT $\alpha$ his34200 trp1::hisG ura3-167 Ty1his3AI) [52] by replacing the trp1::hisG allele using a TRP1 PCR product, and then by disrupting the LEU2 gene using the pRS406 URA3-integrating vector [53] harboring a fragment of the LEU2 open reading frame (positions 153-898) to generate a leu2-URA3-leu2 allele. These transformants were selected for $\mathrm{Trp}^{+}$or $\mathrm{Ura}^{+} \mathrm{Leu}^{-}$phenotypes, respectively. JC5516 is a derivative of BY4741 (MATa his3 1 leu $2 \Delta 0$ met $15 \Delta 0$ ura $3 \Delta 0$ ) that harbors a partial deletion allele of $k a n M X$ in place of the TRP1 open reading frame (trp1::kanMX $\triangle N s i I$ ), partial deletion of CAN1 at its normal location (can1 $\Delta 1$, lacking positions 84-1427 of the open reading frame), insertion of TRP1 on the left arm of chromosome VIII, and insertions of CAN1, HIS3, and URA3 on the right arm of chromosome VIII, as described previously [35]. Derivatives of JC5516 deficient for the RAD52 gene were generated by replacing the wild type allele with a $k a n M X$ allele amplified from the $S$. cerevisiae MATa deletion collection (Thermo Scientific Open Biosystems). PCR was used to verify presence of the deletion allele and absence of the wild type allele, and three independent transformants were analyzed.

\section{Genomic instability rates}

Fluctuation tests [54] to measure rates of mutations, recombination, or retrotransposition per cell generation were conducted by inoculating 5,000 cells into each of seven to ten one ml samples of each type of liquid medium indicated in the figures and growing cells in culture tubes on rotators for three days at $20^{\circ} \mathrm{C}$ or for $24 \mathrm{~h}$ at $30{ }^{\circ} \mathrm{C}$. Cells inoculated into media containing $200 \mu \mathrm{M}$ (0.0022 \%) methyl methanesulfonate (MMS) or $30 \mathrm{mM}$ hydroxyurea (HU) were allowed to grow for four days at $20{ }^{\circ} \mathrm{C}$ or $28-30 \mathrm{~h}$ at $30{ }^{\circ} \mathrm{C}$. Incubations were up to twice as long for $0.2 \%$ glucose medium and medium containing non-fermentable carbons sources (acetate, ethanol, or glycerol) to achieve comparable cell densities. After growth, appropriate dilutions of cells were spread onto solid SC +
$2 \%$ glucose medium to determine colony-forming units/ $\mathrm{ml}$. Appropriate volumes of each culture were spread onto solid SC + $2 \%$ glucose lacking arginine with $60 \mu \mathrm{g} / \mathrm{ml}$ canavanine to select for mutations in the CAN1 gene [55], onto $\mathrm{SC}+2 \%$ glucose with $1 \mathrm{mg} / \mathrm{ml} 5$-fluoroorotic acid (FOA) to select for mutations in the URA3 gene [56], onto $\mathrm{SC}+2 \%$ glucose lacking leucine to select for recombination at the leu2-URA3-leu2 locus to regenerate a LEU2 allele (see SCE218 strain description), and onto SC + $2 \%$ glucose lacking histidine to select for retrotransposition of a chromosomal Ty1 element harboring the his $3 A I$ retromobility indicator gene [57], as appropriate for the strain background. Plates were incubated for four days at $30{ }^{\circ} \mathrm{C}$ prior to counting colonies. Rate values were determined using the Ma-Sandri-Sarkar maximum likelihood estimator calculated through FALCOR [58], and were corrected based on the fraction of each culture assayed, as previously described $[54,58]$. The number of independent trials analyzed for each condition is given in the relevant figure legends.

\section{Chronological aging experiments}

Duplicate cultures of SCE218 or JC5516 were initiated at 5,000 cells $/ \mathrm{ml}$ in five $\mathrm{ml}$ of YPD medium or the alternative media indicated in the figures in glass culture tubes and incubated on a rotator at $20{ }^{\circ} \mathrm{C}$, except for samples grown at $30{ }^{\circ} \mathrm{C}$ to test the effects of temperature. Populations were initially sampled every three to five days, and then every seven days until the viability of the control cultures dropped below $10 \%$. Cell viability was determined by trypan blue dye exclusion, as previously described [35], and three trials were performed for each strain and growth condition.

\section{Analysis of CAN1 and URA3 mutations}

Mutations in the CAN1 and URA3 genes were categorized as small or large-scale mutations based on PCR or phenotypic screens. Representative colonies from cultures in individual mutation rates trials were patched onto $\mathrm{SC}$ arginine $+2 \%$ glucose $+60 \mu \mathrm{g} / \mathrm{ml}$ canavanine or $\mathrm{SC}+2 \%$ glucose $+1 \mathrm{mg} / \mathrm{ml} \mathrm{FOA}$, as appropriate. Each derivative tested for strain SCE218 was from an independent culture, and no more than two (URA3 mutations) or three (CAN1 mutations) derivatives from given independent cultures were tested for JC5516. PCR for the CAN1 gene in strain SCE218 or for the URA3 gene in JC5516 was performed using cells directly as templates or using DNA extracted by glass bead disruption and phenol-chloroform extraction and the following primers (sequences written $5^{\prime}$ to $3^{\prime}$ ): CAN1 - GCAAAGGCCACAGAACCGTATTC and GCG AAATGGCGTGGAAATGTGATC, URA3 - AGCACCCG AACCGAGTGTCCA (matches chromosome VIII sequence nearby URA3 insertion site) and ACGTTCA CCCTCTACCTTAGC. Mutants that yielded a PCR 
product were scored as having small-scale mutations, and those that did not yield a product were scored as having large-scale mutations. A control primer pair to a single copy gene was included in each PCR to verify that negative results were not due technical failure to amplify a template. The HIS3 gene is present immediately adjacent to CAN1 in JC5516 [35], and patches of representative canavanineresistant colonies from individual cultures in this background were replicated to SC-histidine $+2 \%$ glucose medium to determine whether a functional copy of HIS3 was present. Patches with a $\mathrm{His}^{+}$prototroph phenotype that retained HIS3 were considered to have small-scale mutations in CAN1, while His patches were considered to have lost both CAN1 and HIS3. PCR primers used to test for the loss of additional sequences surrounding the site of CAN1 insertion on chromosome VIII and for nonreciprocal translocations involving sequences from chromosome I included the primers for URA3 listed above, HIS3 - ATGACAGAGCAGAAAGCCCTAG and CTTTGGTGGAGGGAACATCGTTG (these primers also amplify the his $3 \triangle 1$ allele in this strain), FLO5 - ATG ACAATTGCACACCACTGC, ACGCCGCTAACAGTAA CGGTG, IMD2 - GCTCAAGTGGGTCAAAGAGAG and GTAAGAATGTAAATTATGAACG, CTTGGTAGGCTC TTGGTAAAG, YHRCTy1-1 - GTTCATCATCAGTGAT CTGACG, for additional sites on chromosome VIII - AA AGGTTTGTCACGAGCACCG, TGTTGGAATAAGACT CAACTGCGA, CAGCTTCAATGTGGTAAACGGA, GG ATTCTCATAAGAAAGTCCAGAG, and for sites on chromosome I - GCCAACATCAATTAATCAACTTTC CC, CGTCTACAGAGTATAGTGTAG, TCGTAGC GAGGACTGCTAAGG, GGATTCTCATAAGAAAGT CCAGAT.

\section{Statistical analyses}

Significant differences in mean rates compared to control values were determined using unpaired two-tailed $t$ tests assuming equal or unequal variance, as appropriate for the data being compared. Fisher's exact test was used to determine if ratios were significantly different. Levels of significance are indicated in the figure legends.

\section{Results}

Not all lifespan-altering growth conditions produced expected changes in chronological lifespan of two strains from different backgrounds aged at $20^{\circ} \mathrm{C}$

Many growth conditions previously reported to alter lifespan did not yield expected changes in mutation rates in young cell populations in initial experiments, so the chronological lifespans of the SCE218 and JC5516 strains in all alternative growth conditions were compared to lifespan in control rich (YPD) medium. YPD was chosen as the control medium rather than synthetic medium (SC) that is often used for chronological aging because YPD has a standard glucose concentration (2\%) to avoid calorie restriction or excess in the control condition, and since acetic acid accumulation in SC shortens lifespan [45], and the intent was to include at least some growth conditions that influenced lifespan independently of acetic acid. Cells were grown at $20{ }^{\circ} \mathrm{C}$, rather than the standard $30{ }^{\circ} \mathrm{C}$, for aging and mutation rate experiments, except when temperature was tested. This lower temperature was used since retrotransposition of yeast Ty1 elements is associated with aging and occurs more frequently at $20{ }^{\circ} \mathrm{C}$ than at $30{ }^{\circ} \mathrm{C}[35,38$, $39,59,60]$. Ty1 retrotransposition is a source of mutations, so use of the lower growth temperature allowed Ty1 to potentially contribute to any changes in mutation rates. The goal was to identify growth conditions that changed the lifespan of these yeast strains relative to growth in YPD at $20{ }^{\circ} \mathrm{C}$ and to measure rates of genomic instability using those conditions, rather than to try to recapitulate specific effects observed using growth at $30{ }^{\circ} \mathrm{C}$ or in SC medium as a control condition. Prior work has shown that CLS is reduced by a few changes to standard growth conditions, including the presence of a high glucose concentration in either SC or YPD medium $[44,46]$, growth in SC leading to accumulation of acetic acid [45], and increased growth temperature using SC medium [44]. Replicative and chronological lifespan are both extended by YPD medium with a low glucose concentration [47, 61], CLS is extended in SC medium with a low glucose concentration [44, 45], and CLS is extended in SC medium containing only a nonfermentable carbon source (such as ethanol or glycerol) $[44,45]$ or SC medium with high osmolarity (such as $0.3 \mathrm{M}$ sodium chloride) [44, 62]. Cell viability was directly determined using trypan blue dye exclusion, which has previously been used to evaluate changes in chronological lifespan and yields relative changes in lifespan similar to those obtained by measuring colony-forming units [35, 63-65].

Most growth conditions resulted in the expected lifespan changes in the SCE218 strain background. Three growth conditions expected to shorten lifespan did result in significantly shorter lifespans in SCE218 (Fig. 1a and Additional file 1: Table S1). Growth in SC $+2 \%$ glucose medium resulted in the shortest lifespan, with a significant drop in viability at all time points beginning with day eight. Growth at $30{ }^{\circ} \mathrm{C}$ led to a significant decrease in viability at day eight, and growth at $30^{\circ} \mathrm{C}$ and in YP $+10 \%$ glucose both showed significant reductions in viability from day 28 until those populations dropped below $10 \%$ viability. Three of four growth conditions expected to lengthen lifespan resulted in improved viability during chronological aging of strain SCE218 (Fig. 1b and Additional file 1: Table S1). Significantly higher viability was observed at day 21 and most or all time points 


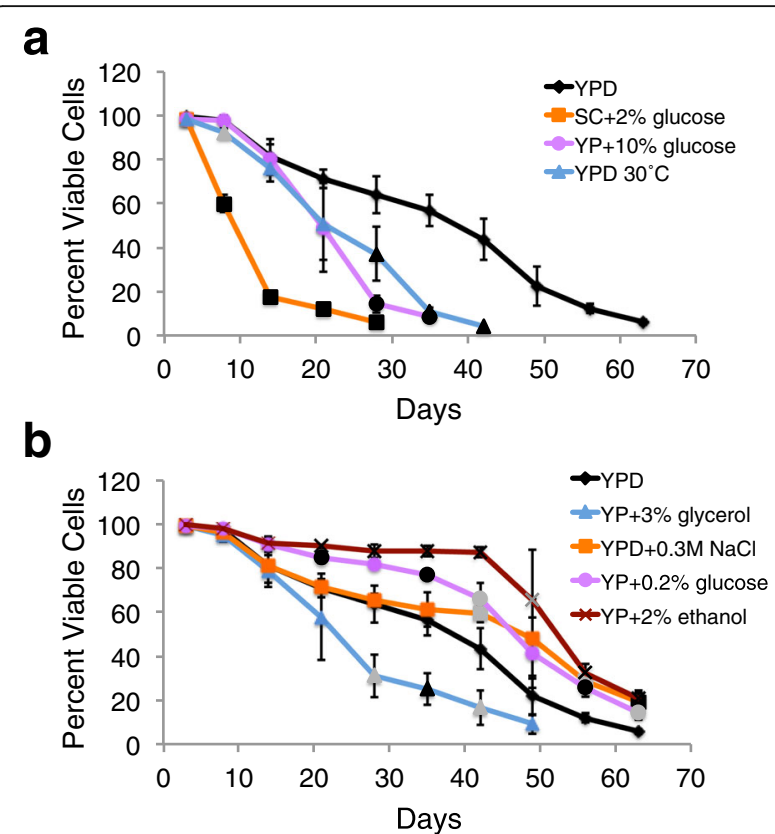

Fig. 1 Most growth conditions altered lifespan in strain SCE218 (GRF167 background) as expected. Day zero is when cultures were inoculated, and viability was determined beginning at day three by trypan blue dye exclusion during chronological aging at $20^{\circ} \mathrm{C}$ in control YPD medium or in the alternative growth conditions indicated for strain SCE218. $\mathbf{a}$ and $\mathbf{b}$ show data for treatments that were expected to shorten or lengthen lifespan, respectively, compared to the same set of data for control medium. Mean and standard deviation of three trials for each condition are shown. Gray or black symbols on the lines for alternative growth conditions indicate time points at which viability differed significantly from the control, with $p<0.05$ or 0.01 , respectively

thereafter for cells grown in YP $+0.2 \%$ glucose or YP + $2 \%$ ethanol, while significantly higher viability was observed at multiple time points beginning with day 42 for cells grown in YPD $+0.3 \mathrm{M} \mathrm{NaCl}$. Growth in YP $+3 \%$ glycerol as a carbon source provided the only exception, which resulted in a significant drop in viability beginning with day 28 .

The three growth conditions predicted to shorten lifespan had the expected effect on aging of strain JC5516, but fewer treatments extended lifespan of this strain (Fig. 2 and Additional file 1: Table S1). Viability was significantly decreased for JC5516 grown in SC $+2 \%$ glucose, at $30{ }^{\circ} \mathrm{C}$, or in $\mathrm{YP}+10 \%$ glucose beginning at day six, six and 18 , or 25 , respectively, and continuing for the remainder of the experiments (Fig. 2a). However, significantly reduced viability was also observed for cells grown in YPD $+0.3 \mathrm{M} \mathrm{NaCl}$ from days 11 to 60 and for cells grown in $\mathrm{YP}+3 \%$ potassium acetate beginning at day 32, even though these treatments were expected to lengthen lifespan (Fig. 2b). While growth to stationary phase in acetate medium (as opposed to shifting growing cells or stationary phase cells to medium with acetate) has not previously been reported to extend CLS, acetate

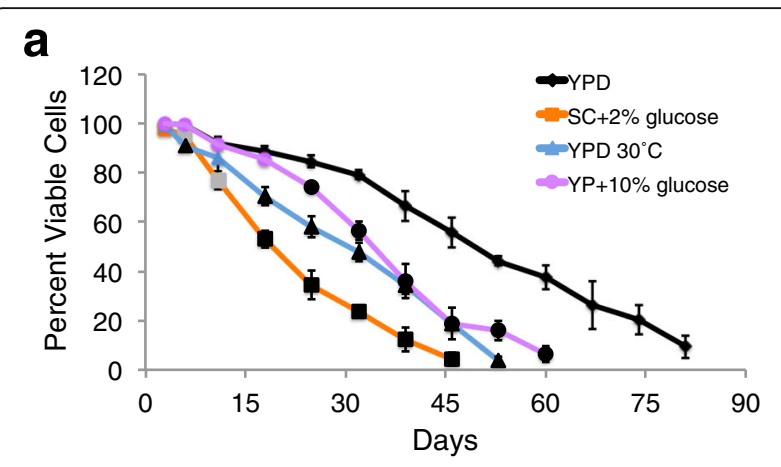

b

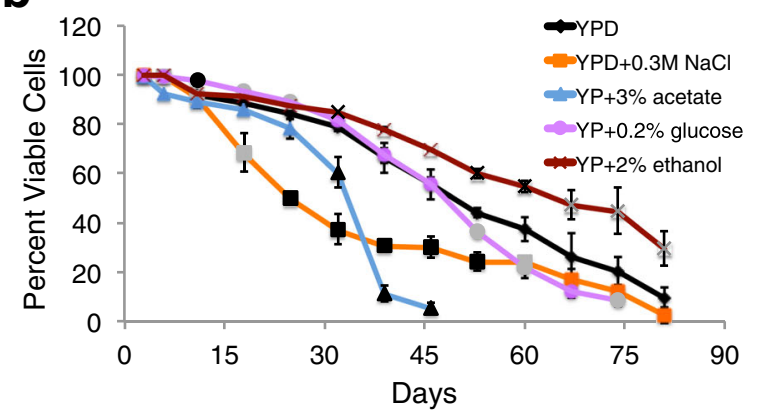

C

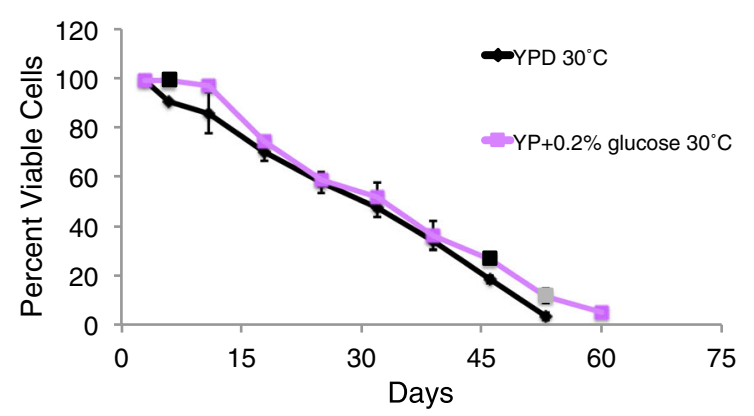

Fig. 2 Most alternative growth conditions shortened lifespan in strain JC5516 (BY4741 strain background). Day zero is when cultures were inoculated, and viability for strain JC5516 was determined beginning on day three by trypan blue dye exclusion during chronological aging at $20^{\circ} \mathrm{C}$ in control YPD medium or in alternative growth conditions initially expected to shorten $\mathbf{a}$ or lengthen $\mathbf{b}$ lifespan is shown. Panel c compares the YPD $30^{\circ} \mathrm{C}$ data shown in a to cells grown in low glucose at $30^{\circ} \mathrm{C}$. Mean and standard deviation of three trials for each condition are shown, and significant differences are indicated as for Fig. 1

was used as an alternative non-fermentable carbon source with JC5516 because of the negative influence of glycerol on the lifespan of strain SCE218. Growth of JC5516 in YP + $0.2 \%$ glucose significantly improved viability at days 11 to 25 , but viability then significantly decreased beginning at day 53 (Fig. 2b). Only growth in $\mathrm{YP}+2 \%$ ethanol consistently extended lifespan, with significantly increased viability at day 32 and then day 53 through the rest of the time points (Fig. 2b). For the subsequent comparisons to mutation rates, low glucose was categorized as having a positive influence on lifespan because of improved viability early during aging, 
but any potential influence of growth in low glucose on mutation rates would be expected to be much less than the influence of growth in ethanol. Differences from the anticipated outcomes for some alternative growth conditions may be the result of both strain and temperaturespecific effects, since growth of JC5516 in YP + $0.2 \%$ glucose at $30{ }^{\circ} \mathrm{C}$ modestly but consistently extended lifespan compared to YPD at $30^{\circ} \mathrm{C}$ (Fig. 2c).

\section{No correlation between direct-repeat recombination,} retrotransposition, or mutation rates in young cells and growth conditions that alter lifespan in strain SCE218 (GRF167 background)

Strain SCE218 harbors a wild type allele of the counter-selectable CAN1 gene at its normal location on the left arm of chromosome $\mathrm{V}$, truncated and partially duplicated alleles of LEU2 interrupted by $U R A 3$ and plasmid sequences at the normal location of LEU2 on the left arm of chromosome III (Fig. 3a), and a chromosomal copy of a Ty1 retrotransposon marked with the his $3 A I$ retromobility indicator gene [57] (Fig. 3b). This strain can be used to quantify lossof-function mutations in CAN1 by detection of canavanine-resistant cells and direct-repeat recombination by detection of $\mathrm{Leu}^{+}$prototrophs resulting from recombination between the truncated leu 2 alleles to reconstitute a wild type LEU2 allele (Fig. 3a). Mobility of the Ty1his $3 A I$ retrotransposon can be detected when the intron within his $3 A I$ is spliced out during Ty1 replication and a reverse-transcribed Ty1HIS3 element inserts into the genome, giving rise to a cell that is a $\mathrm{His}^{+}$prototroph (Fig. 3b).

\section{a}

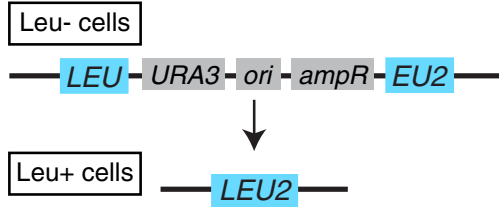

b

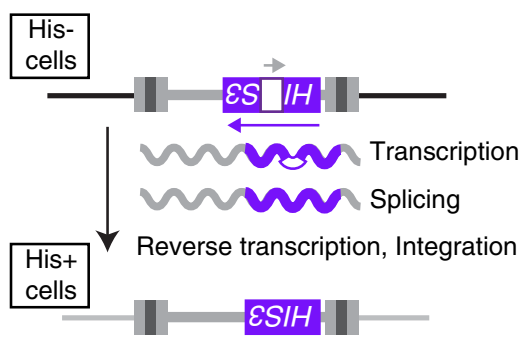

C
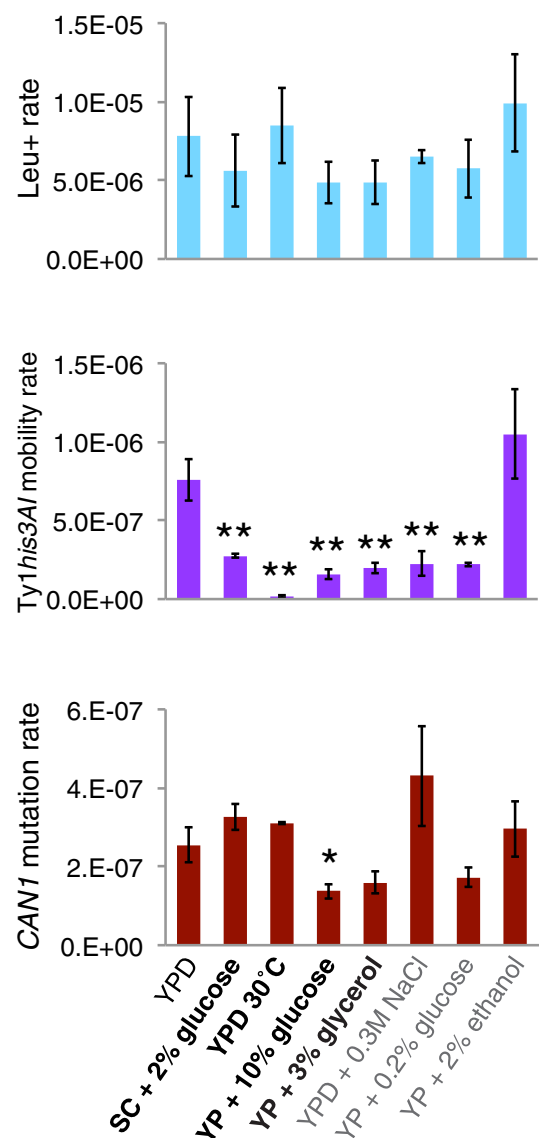

Fig. 3 No correlation between recombination, retrotransposition, or CAN1 mutations and lifespan-altering treatments in strain SCE218. a Assay for recombination between two truncated alleles of the LEU2 gene with overlapping sequences that removes intervening plasmid sequences and restores a wild type LEU2 allele, conferring a Leu ${ }^{+}$prototroph phenotype. $\mathbf{b}$ Assay for retromobility of a chromosomal Ty1 his3Al element. Expression of Ty1 his $3 \mathrm{Al}$ allows splicing of an artificial intron present in the opposite transcriptional orientation of the HIS3 gene, reverse transcription, and insertion of a Ty1HIS3 cDNA into the genome, conferring a His ${ }^{+}$prototroph phenotype. (c) Rate values for the indicated forms of genomic instability obtained from fluctuation tests for cells grown for three days in control YPD broth at $20^{\circ} \mathrm{C}$ or using the indicated conditions that shortened (bold) or lengthened (gray) lifespan in the SCE218 strain. Mean and standard deviation for four control trials and two trials in each alternative condition are shown. Asterisks indicate level of significance: ${ }^{*}=p<0.05,{ }^{* *}=p<0.01$ 
Recombination rates to reconstitute LEU2 were not significantly altered by any of the growth conditions tested, a number of conditions significantly reduced Ty1his $3 A I$ mobility, and only one condition significantly altered CAN1 mutation rate (Fig. 3c and Additional file 2: Table S2). All four conditions that shortened SCE218 lifespan reduced the rate of Ty1his3AI retromobility, but two of the three conditions that lengthened SCE218 lifespan also reduced Ty1 mobility (Fig. 3c). The similarity in the effects of both types of conditions does not support a role for changes in Ty1 retromobility mediating the lifespan effects of these treatments. Analysis of 28 independent canavanineresistant derivatives from cells grown in YPD and 19-20 independent derivatives for cells grown in each of the other growth conditions for the presence of the CAN1 gene resulted in amplification of a $C A N 1$ product of the expected size from 89-100 \% of derivatives (Additional file 3: Table S3), indicating that small-scale mutations were present in nearly all cases. Overall, growth conditions that alter lifespan did not produce expected changes in mutation rates in young cells for strain SCE218.

\section{Mutation rate at one locus in strain JC5516 (BY4741 background) shows a strong correlation with growth conditions that alter the rate of aging}

Rates of CAN1 and URA3 mutations in growth conditions that alter lifespan were measured using strain JC5516. This strain has a complete deletion of URA3 and a partial deletion of CAN1 from their normal genomic locations, and insertions of URA3 and CAN1 approximately $40 \mathrm{kbp}$ and $26 \mathrm{kbp}$ from the end of the right arm of chromosome VIII, respectively [35] (positions 522,206 and 536,834 on chromosome VIII in the reference $S$. cerevisiae genome [66], Fig. 4a).

CAN1 mutation rates were significantly different in all lifespan-altering growth conditions tested (Fig. 4b and Additional file 2: Table S2). The five conditions that were shown to reduce JC5516 viability during chronological aging all increased the CAN1 mutation rate from 2.1 to 5.5 -fold. The largest increase was observed for $\mathrm{SC}+2 \%$ glucose, which had the strongest negative effect on lifespan, followed by YPD at $30{ }^{\circ} \mathrm{C}$, which also quickly led to decreased viability in the lifespan experiments (Fig. 4b and Fig. 2a). The smaller effects of $\mathrm{YP}+10 \%$ glucose, $\mathrm{YP}+3 \%$ acetate, or YPD $+0.3 \mathrm{M} \mathrm{NaCl}$ on CAN1 mutation rate are consistent with their less negative influences on lifespan. Growth in YP $+2 \%$ ethanol reduced the CAN1 mutation rate 7.7 -fold, consistent with the positive influence of ethanol on lifespan, while growth in YP $+0.2 \%$ glucose only reduced the rate 2.5 -fold, consistent with the very modest positive influence of low glucose early during lifespan in JC5516 (Fig. 4b and Fig. 2a).
The CAN1 mutation rate was much higher (24-fold) when CAN1 was located on chromosome VIII in JC5516 than when it was at its normal location on chromosome $\mathrm{V}$ in SCE218 (compare Fig. 3c and Fig. 4b). Only 24\% of JC5516 canavanine-resistant derivatives from control cultures retained function of the neighboring HIS3 gene, which was also inserted onto the right arm of chromosome VIII in this strain [35] (Fig. 4a), as determined by transferring cells to medium lacking histidine (Table 1). This indicates that most of these mutations were not small-scale changes in the CAN1 locus. The frequency of small-scale CAN1 mutations was modestly elevated for cells grown in YP $+2 \%$ ethanol, but was unchanged in the other growth conditions (Table 1).

URA3 mutation rates were significantly reduced by both conditions that had a positive influence on lifespan in JC5516, but were also reduced by three of the conditions that shortened lifespan (Fig. 4c and Additional file 2: Table S2). None of the conditions that shortened lifespan increased the URA3 mutation rate. Decreases in the rate ranged from 1.7 to 5.5 -fold, with growth in $\mathrm{YP}+2 \%$ ethanol producing the greatest decrease. PCR for the presence of $U R A 3$ with cells or DNA extracted from representative FOA-resistant derivatives from each of the growth conditions indicated that nearly all mutations in URA3 were small-scale (Table 1). This is similar to what was observed for CAN1 in SCE218, but contrasts with the results for CAN1 in JC5516. Modest but significant decreases in the proportion of URA3 mutants with small-scale changes were observed when cells were grown in $\mathrm{YP}+2 \%$ ethanol or YP $+3 \%$ acetate (Table 1 ).

CAN1 and URA3 mutation rates were then compared following chronic exposure to $200 \mu \mathrm{M}$ (0.0022 \%) MMS in all growth conditions to determine if the alternative growth conditions would exacerbate or ameliorate the effects of an exogenous DNA damaging agent (Fig. 4d and e, Additional file 4: Table S4). This concentration of MMS caused only a modest decrease in growth rate of the cells, requiring four days of growth at $20{ }^{\circ} \mathrm{C}$ in YPD to achieve similar cell densities to those obtained after three days of growth without MMS. Treatment with MMS caused a significant 2.1-fold increase in CAN1 mutation rate in YPD medium (compare Fig. $4 \mathrm{~b}$ and $\mathrm{d}$ and see Fig. 5a). Only $\mathrm{SC}+2 \%$ glucose and $\mathrm{YP}+3 \%$ acetate led to further significant increases in the CAN1 mutation rate, of 3.4 and 2.7 -fold, respectively (Fig. 4d). The other three conditions determined to shorten lifespan in JC5516 led to further increases of less than two-fold that were not significant. Growth in $\mathrm{YP}+$ $0.2 \%$ glucose or $\mathrm{YP}+2 \%$ ethanol decreased CAN1 mutation rate in the presence of MMS by 3.9 or 12fold respectively, which were greater fold-decreases than observed for these growth conditions in the absence of MMS (compare Fig. 4b and d). Overall, four 
a

Chr VIII

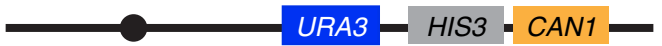

b

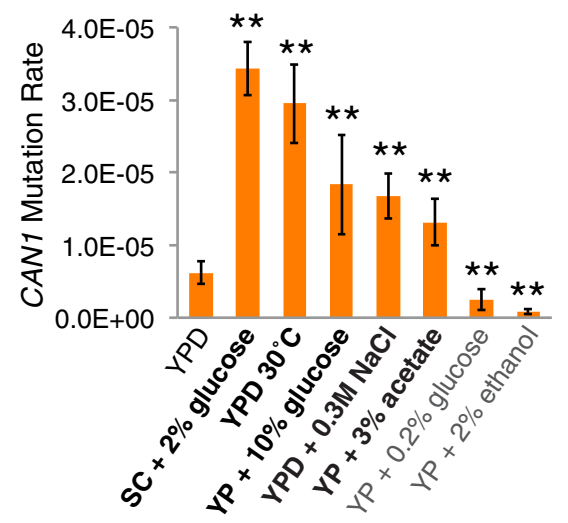

d

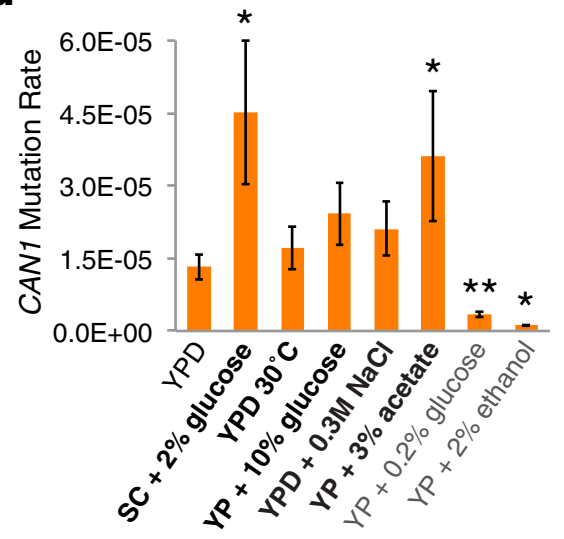

C

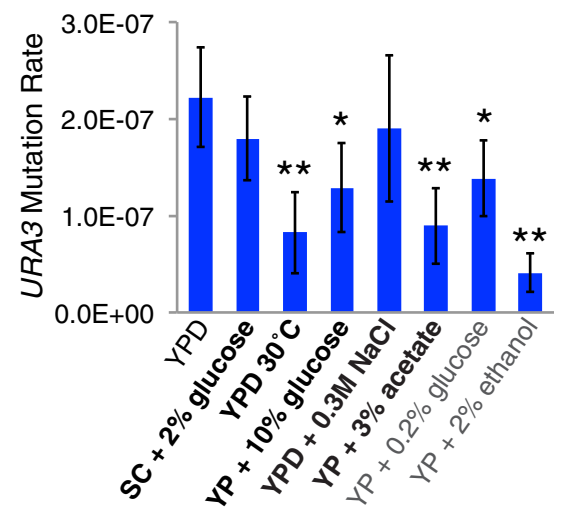

e

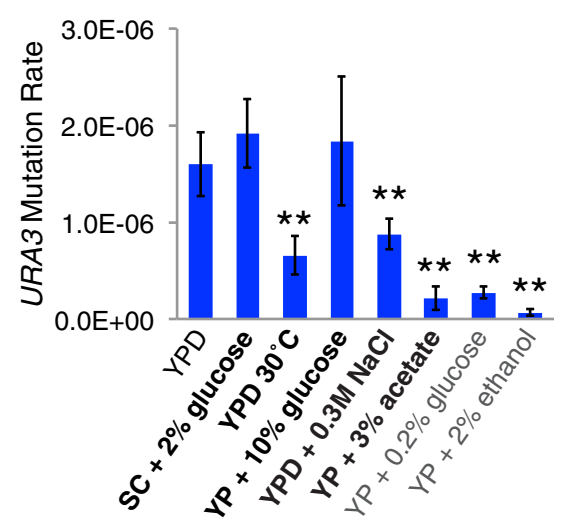

Fig. 4 CAN1 mutation rates in strain JC5516 are strongly correlated with lifespan-altering treatments. a Illustration of the relative positions of URA3, HIS3, and CAN1 genes inserted onto the distal portion of the right arm of chromosome VIII in the JC5516 strain. b CAN1 mutation rates after growth for three days in control YPD broth at $20^{\circ} \mathrm{C}$ or in the indicated growth conditions that were found to shorten lifespan (bold) or lengthen lifespan (gray) of strain JC5516. c URA3 mutation rates after growth for three days in control YPD broth at $20^{\circ} \mathrm{C}$ or the same conditions as for panel b. $\mathbf{d}$ and $\mathbf{e}$ CAN1 d or URA3 e mutation rates after four days of growth in the same conditions as panels $\mathbf{a}$ and $\mathbf{b}$ with chronic exposure to $200 \mu \mathrm{M}(0.0022 \%)$ MMS. Mean and standard deviations for six or seven trials in YPD and three to five trials in alternative media conditions (b and $\mathbf{c}$ ) or three to four trials with MMS treatment ( $\mathbf{d}$ and $\mathbf{e}$ ) are shown. Note the change in $\mathrm{y}$-axis scales between panels $\mathbf{b}$ and $\mathbf{d}$ and panels $\mathbf{c}$ and $\mathbf{e}$. Asterisks indicate level of significance: ${ }^{*}=p<0.05$, ${ }^{* *}=p<0.01$

of the seven conditions exacerbated or ameliorated the effect of MMS. The influences of the growth conditions that shortened lifespan were less consistent, though, than what was observed in the absence of MMS treatment.

MMS treatment caused a 7.2-fold increase in the URA3 mutation rate, which is substantially greater than the increase observed with the CAN1 mutation rate (Fig. $5 \mathrm{a}$ and $\mathrm{b}$ ). None of the conditions shown to shorten JC5516 lifespan further increased the MMS-induced URA3 mutation rate, and growth at $30{ }^{\circ} \mathrm{C}$, in YPD + $0.3 \mathrm{M} \mathrm{NaCl}$, or in $\mathrm{YP}+3 \%$ acetate instead caused 2.4,
1.9 , or 7.5 -fold decreases in the MMS-induced URA3 mutation rate, respectively (Fig. 4e). Growth in YP + $0.2 \%$ glucose or YP $+2 \%$ ethanol did lead to greater reductions in the MMS-induced URA3 mutation rate, of 5.9 and 24-fold, respectively, than the corresponding reductions observed without MMS-treatment (Fig. 4c and e). Exposure to MMS did not lead to an improved correspondence between the growth conditions and their predicted effects on URA3 mutation rate, considering that the lifespan-shortening conditions did not lead to increases in the mutation rate in the absence or presence of MMS. 
Table 1 Mutations in CAN1 are mostly large-scale changes, while mutations in URA3 are mostly small-scale changes

\begin{tabular}{|c|c|c|c|c|c|c|c|c|}
\hline \multirow[t]{3}{*}{ Sample } & \multicolumn{4}{|c|}{ CAN1 mutations } & \multicolumn{4}{|c|}{ URA3 mutations } \\
\hline & \multicolumn{2}{|c|}{ Untreated } & \multicolumn{2}{|c|}{$+\mathrm{MMS}^{a}$} & \multicolumn{2}{|c|}{ Untreated } & \multicolumn{2}{|c|}{$+\mathrm{MMS}^{a}$} \\
\hline & $N$ & Freq $\mathrm{His}^{+}$ & N & Freq $\mathrm{His}^{+}$ & $\bar{N}$ & Freq point Mutations $^{b}$ & $\bar{N}$ & Freq point mutations $^{b}$ \\
\hline YPD & 217 & 0.24 & 110 & 0.46 & 99 & 0.95 & 43 & 0.98 \\
\hline SC $+2 \%$ Glucose & 137 & 0.24 & 80 & 0.41 & 57 & 1.0 & 13 & 0.92 \\
\hline $30{ }^{\circ} \mathrm{C}$ & 102 & 0.28 & 66 & 0.47 & 27 & 0.96 & 16 & 1.0 \\
\hline $10 \%$ Glucose & 111 & 0.21 & 83 & 0.46 & 33 & 0.97 & 50 & 0.94 \\
\hline $0.3 \mathrm{M} \mathrm{NaCl}$ & 135 & 0.26 & 81 & 0.41 & 46 & 1.0 & 39 & 0.97 \\
\hline $3 \%$ Acetate & 98 & 0.18 & 78 & 0.33 & 37 & $0.81^{*}$ & 19 & 1.0 \\
\hline $0.2 \%$ Glucose & 106 & 0.27 & 82 & 0.38 & 38 & 0.87 & 50 & 0.96 \\
\hline 2 \% Ethanol & 108 & $0.39^{* *}$ & 96 & 0.34 & 46 & $0.80^{*}$ & 40 & 0.95 \\
\hline YPD rad52 $\triangle$ & 59 & $0.88^{* * *}$ & $N T^{c}$ & $N T^{c}$ & 25 & 0.96 & $N T^{c}$ & $N T^{c}$ \\
\hline
\end{tabular}

${ }^{a}$ Chronic exposure to $200 \mu \mathrm{M}(0.0022 \%)$ MMS

${ }^{b} \mathrm{~S}$ cored as point mutation if yielded expected size URA3 PCR product

'Not tested

Asterisks indicate levels of significance: ${ }^{*}=p<0.05,{ }^{* *}=p<0.01,{ }^{* * *}=p<0.001$

\section{CAN1 mutations in JC5516 are large-scale recombination events}

The types of mutation events leading to CAN1 mutations in JC5516 were explored in more detail, since the mutations occurred at a high rate and growth in alternative conditions yielded expected changes in the CAN1 mutation rate. The preliminary analysis shown in Table 1 indicated that most of the CAN1 mutations were largescale events that resulted in loss of function of CAN1 and the neighboring HIS3 gene. Deletions of chromosome segments are usually rare compared to small-scale mutations, but homologous recombination-based events could potentially delete/replace the CAN1 and HIS3 sequences at a relatively high rate. Since JC5516 is a haploid strain, homologous recombination events would be expected to require the presence of suitable non-allelic homologous sequences to delete or replace the relevant region of chromosome VIII. Recombination-based events might also be more sensitive to DNA replication stress, since template switching to non-allelic homologous sequences during replication could give rise to such events [67].

Growth in SC + $2 \%$ glucose leads to shortened lifespan due to accumulation of acetic acid in the medium, and suspension of stationary phase yeast cells in water containing $10 \mathrm{mM}$ acetic acid shortens their lifespan relative to suspension in water only [45]. Acetic acid has also been shown to increase DNA replication stress in yeast [68]. Growth of JC5516 in YPD with $10 \mathrm{mM}$ acetic acid increased CAN1 mutation rate five-fold, but did not increase the URA3 mutation rate (Fig. $5 \mathrm{a}$ and b), similar to the results for growth in $\mathrm{SC}+2 \%$ glucose (Fig. $4 \mathrm{~b}$ and c).
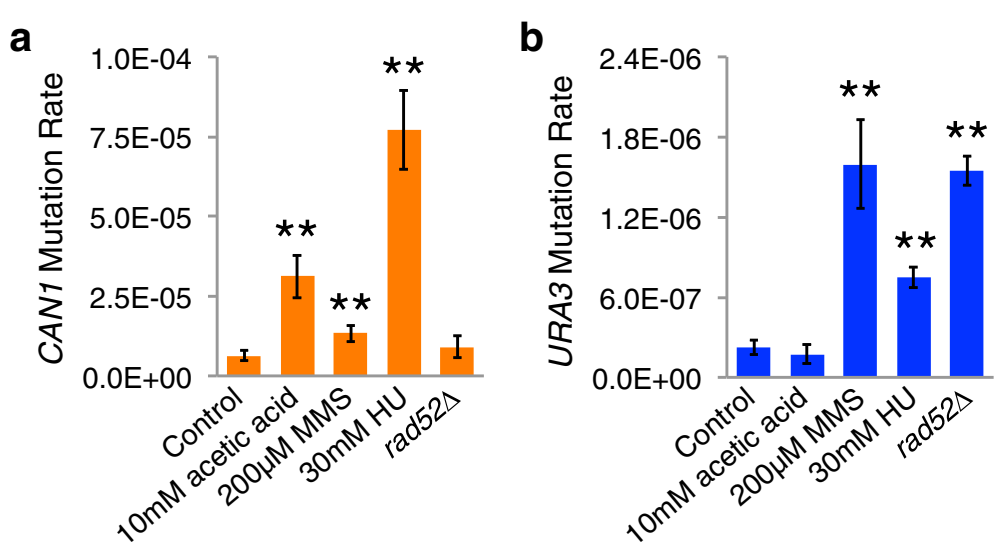

Fig. 5 CAN1 mutations in JC5516 are greatly elevated by DNA replication stress. Mean and standard deviation for CAN1 (a) or URA3 (b) mutation rates in JC5516 grown for three days at $20^{\circ} \mathrm{C}$ (or four days for HU and MMS) in standard rich YPD medium (Control), in YPD with chronic exposure to $10 \mathrm{mM}$ acetic acid, $30 \mathrm{mM} \mathrm{HU}$, or $200 \mu \mathrm{M}$ MMS, or in three rad52 $\triangle$ derivatives grown in YPD. Control and MMS data are the same as shown in Fig. 4. Results of three to four trials are shown for treatments and rad52 $\Delta$ mutants. Double asterisks indicate $p<0.01$ versus control 
Cells were also exposed to $30 \mathrm{mM}$ hydroxyurea (HU) to induce a moderate DNA replication stress throughout the growth period, which resulted in a 12-fold increase in CAN1 mutation rate, but only a 3.4-fold increase in URA3 mutation rate (Fig. 5a and b). These results contrast with those of the DNA alkylating agent MMS, which led to only a 2.1-fold increase in CAN1 mutation rate, but a 7.2fold increase in URA3 mutation rate. The increased mutation events with MMS treatment were also associated with an increased proportion of small-scale mutations in YPD and most alternative growth conditions (Table 1), indicating that MMS treatment had little affect on the events leading to simultaneous loss of CAN1 and HIS3 function. These data are consistent with problems during DNA replication contributing to the high rate of CAN1 mutations in JC5516.

Loss of RAD52 function compromises homologous recombination and produces a hypermutation phenotype that is characterized by an increase in base substitutions $[69,70]$. JC5516 rad52 $\Delta$ derivatives had a seven-fold increase in the URA3 mutation rate but no significant change in the CAN1 mutation rate (Fig. 5a and b). Furthermore, most of the CAN1 mutations in the rad52A strains were small-scale changes, based on retention of the function of the neighboring HIS3 gene, in contrast to the low frequency of small-scale changes in the RAD52 parent strain (Table 1). The increase in the proportion of small-scale changes and the absence of a change in the CAN1 mutation rate indicate that loss of RAD52 decreased the rate of large-scale changes causing loss of CAN1 function. The combined data from $\operatorname{rad} 52 \Delta$ mutants, acetic acid treatment, and HU treatment are consistent with the CAN1 mutations in JC5516 largely arising from recombination events associated with DNA replication stress.

The presence or absence of nearby sequences on chromosome VIII was examined by PCR with a set of 29 independent can 1 mutants that were unable to grow on medium lacking histidine. As expected based on their His phenotype, all 29 mutants failed to yield a product corresponding to the HIS3 allele that was originally present immediately centromere-proximal to CAN1. All 29 can1his3 mutants retained the URA3 gene approximately $15 \mathrm{kbp}$ centromere-proximal to CAN1. During analysis of these events, it was noticed that a nearly 16 kbp region encompassing the site at which HIS3 and CAN1 were inserted onto chromosome VIII is a $98 \% \mathrm{se}-$ quence match to a region near the right arm telomere of chromosome I [66] (Fig. 6a). Approximately $5 \mathrm{kbp}$ more sequence after a Ty1 insertion in this region of chromosome VIII, YHRCTy1-1, is a $97 \%$ sequence match to the region of chromosome I, which lacks a Ty1 element (Fig. 6a). In addition, an approximately four kbp region near the left arm telomere of chromosome I is a $93 \%$ match to the region of chromosome VIII encompassing the CAN1 and HIS3 insertions [66] (Fig. 6a). Primers capable of distinguishing between the relevant chromosome VIII and I regions were used to determine whether non-allelic recombination between these two chromosomes contributed to the CAN1 mutations (example PCR results are shown in Fig. 6a).

This PCR analysis identified ten (34\% of events) or eight (28\% of events) non-reciprocal translocations between chromosome VIII and either the right arm or left arm region of chromosome I, respectively (Fig. 6b and Additional file 5: Table S5). These events resulted in fusion of chromosome VIII and I sequences, as well as the loss of the terminal region of the right arm of chromosome VIII, but the translocations occurred at multiple regions of chromosome VIII in each category (Fig. 6b and Additional file 5: Table S5). Precise sites for the transition from chromosome VIII to chromosome I sequences could not be determined because of long stretches of identical sequences on the two chromosomes around the site of the insertion of CAN1 and HIS3 [66]. Two additional events involved nonreciprocal recombination with the chromosome I regions, but distal sequences from chromosome VIII were retained (YHRCTy1-1 and IMD2), consistent with gene conversion recombination with the chromosome I regions (Additional file 5: Table S5). Another two events were not missing any chromosome VIII sequences other than CAN1 and HIS3, but also likely resulted from gene conversion recombination with chromosome I at sites within the sequences that are completely identical between the two chromosomes. Including these last two cases, 22 of the 29 events (76\%) resulted from nonallelic recombination with chromosome I (Additional file 5: Table S5).

The remaining seven events (24\%) had internal deletions on the right arm of chromosome VIII due to recombination between the FLO5 gene and the YHR213W pseudogene that has substantial sequence similarity to FLO5 [66] (Fig. 6b and Additional file 5: Table S5). Junctions occurred between chromosome VIII positions 525,819-526,286 in FLO5 and positions 539162-539629 in $Y H R 213 W$ in the reference genome [66]. All 29 of the events can therefore be explained by non-allelic recombination, indicating that the high frequency of CAN1 mutations in the JC5516 strain is primarily the result of homologous recombination.

\section{Discussion}

The results of only one of five genomic instability assays using two different strain backgrounds was consistent with lifespan-altering growth conditions changing the rate of aging by altering mutation rates in young cells. These results do not contradict data from numerous 

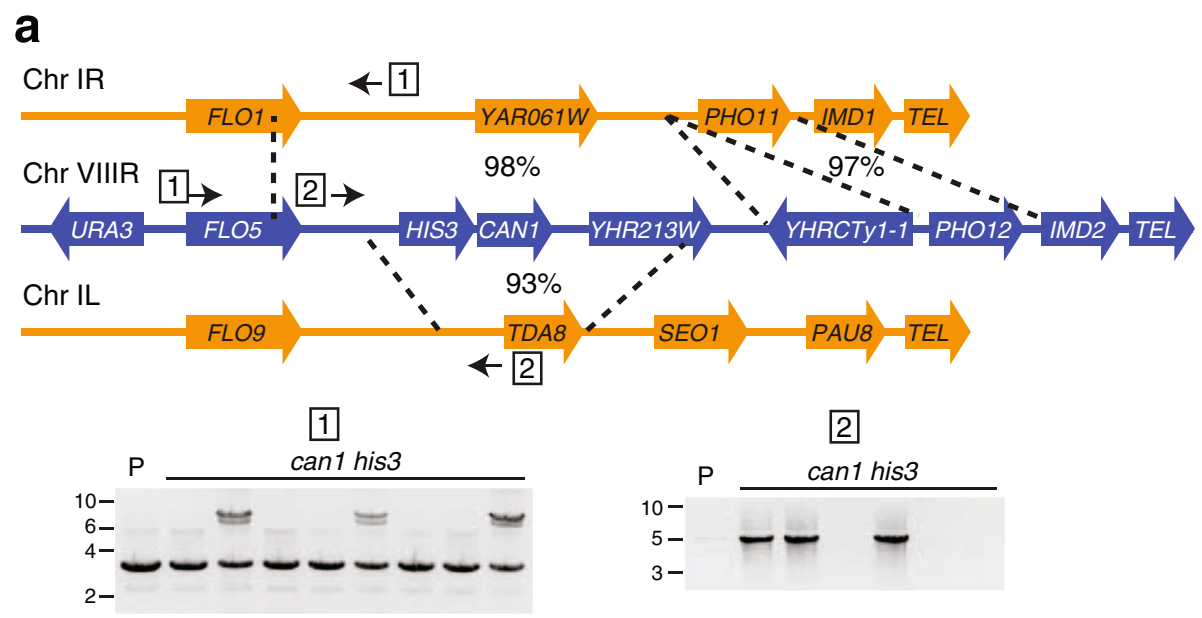

b
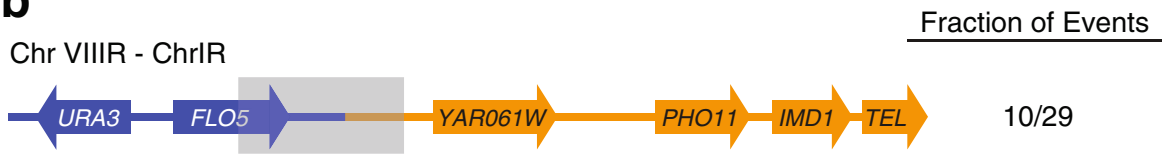

Chr VIIIR - ChrlL

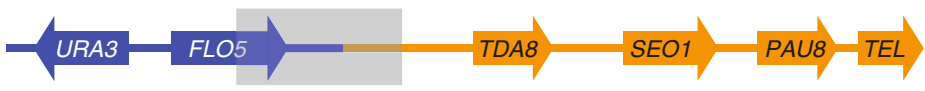

$8 / 29$

Chr VIIIR internal deletion

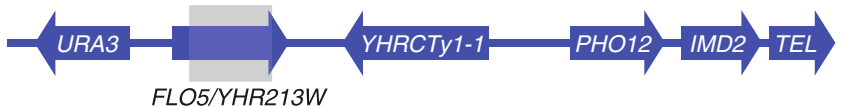

$7 / 29$

Fig. 6 Loss of CAN1 in JC5516 frequently results from non-reciprocal translocations or interstitial deletions. a Drawings of relative positions and orientations of selected gene, pseudogene, and telomeric sequences (TEL) flanking the site of insertion of CAN1 and HIS3 on the right arm of chromosome VIII (blue), as well as selected features for relevant regions from the right and left arms of chromosome I (orange). Dotted vertical lines with percentages indicate sequence identity between regions of chromosomes VIII and I. Boxed numbers and small arrows indicate the relative positions of representative primers used to test for chromosome VIII-I translocations. Representative images of PCR products from the parent strain $(P)$ and independent can1his3 derivatives visualized by staining agarose gels with ethidium bromide (signal inverted) are shown for the two different pairs of primers. The translocation product is the upper product in the left image, and the lower product was generated with a control primer pair to the HSP104 gene at an unrelated chromosome region. Numbers to the left of the images indicate the positions of molecular mass markers in kbp. $\mathbf{b}$ Drawings of the most common non-allelic recombination events identified and their frequency in the total set of events. Gray boxes at the junctions indicate that the precise transitions between FLO5 sequences or sequences between FLO5 and the site of HIS3 on chromosome VIII and chromosome I sequences varied amongst the independent samples. The blue arrow with the gray box for the third class of events indicates a fusion between FLO5 and the YHR213W pseudogene at various sites within each sequence. Sequence features are from the S. cerevisiae reference genome [66]

studies showing that DNA damage and mutations increase with age, since these prior studies in general did not test whether increased DNA damage and mutation frequencies were directly responsible for aging $[6,71]$. The results are also consistent with a recent report that mutation accumulation does not appear to be responsible for limiting the replicative lifespan of dividing yeast mother cells, based on analysis of daughter cell lineages from mothers of different ages [72]. The current study focused on mutations producing a phenotypic effect, rather than all mutations that could be detected by DNA sequencing, since it is likely that mutations would need to have a phenotypic effect at some level in order to affect lifespan.
Not all longevity-altering growth conditions produced the expected effects on lifespan, particularly for strain JC5516. This may be due to strain-specific differences, but also could result from using growth in YPD at $20{ }^{\circ} \mathrm{C}$ as the control condition. Many alternative growth conditions that alter chronological aging have been tested in comparison to growth in $\mathrm{SC}$ at $30{ }^{\circ} \mathrm{C}[44,45]$, and medium acidification is a major determinant of lifespan in SC [45], but not in YPD [46]. For instance, the beneficial effect of glycerol on lifespan in SC is at least partly due to reduced medium acidification but ethanol exposure did not reduce acidification [45], which could explain why glycerol did not extend lifespan similarly to ethanol in rich medium. The increase in yeast CLS 
observed with growth at temperatures below $30{ }^{\circ} \mathrm{C}$ could also have masked or changed the influence of some alternative growth conditions [35, 44]. In addition, acetate was expected to increase CLS because it is a nonfermentable carbon source, but addition of acetate to stationary phase yeast cells in water has been reported to shorten lifespan [73]. Despite some unanticipated lifespan results, it was still possible to test conditions that increased or decreased CLS for influences on mutation rates.

The replication of yeast Ty1 retrotransposons has been associated with elevated genomic instability during chronological aging [35], and retrotransposons from multiple organisms are more highly expressed or mobile with increased age [74-78]. However, no correlation was observed between lifespan-altering conditions and Ty1 mobility in the current data, and it was recently reported that strains with Ty1 retrotransposons did not have shorter CLS than a strain lacking Ty1 retrotransposons when grown in standard rich medium [65]. Ty1 retromobility is also correlated with genomic instability during replicative aging of mother cells, but a direct role for Ty1 in shortening replicative lifespan has not yet been tested [38].

The CAN1 mutation rate in JC5516 was strongly correlated with the lifespan effects of the growth conditions. CAN1 mutation events in JC5516 arose from recombination between non-allelic genomic sites. Many such events could have resulted from use of break-induced replication (BIR) for double-strand break repair or restart of a stalled replication fork, resulting in a DNA replication fork leaving the chromosome VIII template and resuming DNA synthesis on a homologous region of chromosome I or VIII to produce gene conversion and non-reciprocal translocation events or internal deletions, respectively [67]. Alternatively, the interstitial deletions of chromosome VIII that were observed could have resulted from single-stranded annealing (SSA) between homologous sequences flanking CAN1 during DNA repair or replication $[67,79]$.

The results for the chromosome VIII recombination events in JC5516 contrast with the absence of a correlation between direct-repeat recombination events and the alternative growth conditions in strain SCE218. One difference between these recombination events is that identical sequences were involved in the $L E U 2$ recombination events, while the sequences involved in the CAN1 mutation events were only 93-98 \% homologous. The Sgs1p protein in yeast inhibits recombination between sequences that are not identical $[80,81]$. Mutants with a deletion of SGS1 exhibit elevated genome instability during chronological aging, reduced CLS with extreme calorie restriction, and reduced replicative aging [48, 82, 83]. Differential expression or activity of Sgs1p, or other DNA repair factors that suppress recombination between nonidentical sequences, in response to the alternative growth conditions could account for the different results for the two types of recombination events.

Prior work has shown that loss of heterozygosity due to recombination events and large-scale chromosomal alterations increases during yeast replicative aging [36, 37, 39], and that increased DNA replication stress is correlated with decreased yeast CLS $[49,50]$. Several studies have noted that large-scale chromosomal abnormalities, including loss of heterozygosity through interstitial deletions or conversion of one chromosome region by the corresponding region from the homologous chromosome, increase with age in humans [22-25]. In particular, one group noted that their results were consistent with roles for BIR and SSA [22]. The correlation between chromosome changes that likely arise through BIR and SSA and lifespan-altering treatments in yeast indicates that future work in yeast has the potential to provide insights into mechanisms and regulation of chromosomal abnormalities that may prove relevant to human aging.

\section{Conclusions}

These data indicate that changes in the overall accumulation of various mutations early during lifespan are not likely to be directly responsible for the influences of the growth conditions tested on yeast lifespan, but do support the role of DNA replication stress and recombination-based genome rearrangements in yeast aging. It is unclear if the occurrence of homologous recombination-dependent chromosomal deletions and translocations is a direct determinant of lifespan or simply serves as a sign of increased DNA replication stress. Increased recombination is observed in aging yeast mother cells [37] and DNA replication stress is associated with decreased yeast chronological lifespan $[49,50]$. DNA replication stress reduces hematopoietic stem cell function in aging mice [84], and mutations that underlie multiple human segmental progeroid disorders lead to defective DNA replication and chromosomal instability [85-87]. Furthermore, oncogene induced replication stress occurs during early stages of cancer progression and promotes chromosomal deletions and translocations through non-allelic recombination [88]. The current results emphasize the importance of pursuing the role of DNA replication and recombination-based chromosomal instability in aging.

\section{Additional files}

Additional file 1: Table S1. Results of individual chronological lifespan trials for two strain backgrounds in media conditions expected to alter lifespan. (XLSX 43 kb) 
Additional file 2: Table S2. Mutation rates for individual trials in two strain backgrounds in media conditions that alter lifespan. (XLSX 44 kb)

Additional file 3: Table S3. Fraction of canavanine-resistant derivatives in SCE218 that yielded a CAN1 PCR product. (XLSX 27 kb)

Additional file 4: Table S4. Mutation rates for individual trials of JC5516 treated with MMS, acetic acid, HU, or in rad52 $\triangle$ mutants. (XLSX $44 \mathrm{~kb}$ )

Additional file 5: Table S5. Characterization of 29 large-scale CAN1 mutation events in JC5516. (XLSX 44 kb)

\section{Abbreviations}

BIR: Break-induced replication; CLS: Chronological lifespan; HU: Hydroxyurea; kbp: Kilobase pair; MMS: Methyl methanesulfonate; SSA: Single-stranded annealing

\section{Acknowledgements}

The author would like to thank Andreea Musteata for technical assistance.

\section{Funding}

This work was partly supported by grant R00AG031911 from the National Institute on Aging to P. H. M. The article content does not necessarily represent official views of the National Institutes of Health.

\section{Availability of data and materials}

All data are presented in the article and in the additional files.

\section{Competing interests}

The author declares that he has no competing interests.

\section{Consent for publication}

Not applicable.

\section{Ethics approval and consent to participate}

Not applicable.

Received: 22 July 2016 Accepted: 11 October 2016

Published online: 21 October 2016

\section{References}

1. Ramsey MJ, Moore DH, Briner JF, Lee DA, Olsen L, Senft JR, Tucker JD. The effects of age and lifestyle factors on the accumulation of cytogenetic damage as measured by chromosome painting. Mutat Res. 1995;338(1-6):95-106.

2. Lee AT, DeSimone C, Cerami A, Bucala R. Comparative analysis of DNA mutations in lacl transgenic mice with age. FASEB J. 1994;8(8):545-50.

3. Dollé ME, Giese H, Hopkins CL, Martus HJ, Hausdorff JM, Vijg J. Rapid accumulation of genome rearrangements in liver but not in brain of old mice. Nat Genet. 1997;17(4):431-4.

4. Garcia AM, Calder RB, Dollé ME, Lundell M, Kapahi P, Vijg J. Age- and temperature-dependent somatic mutation accumulation in Drosophila melanogaster. PLoS Genet. 2010;6(5):e1000950.

5. Fabrizio P, Battistella L, Vardavas R, Gattazzo C, Liou LL, Diaspro A, Dossen JW, Gralla EB, Longo VD. Superoxide is a mediator of an altruistic aging program in Saccharomyces cerevisiae. J Cell Biol. 2004;166(7):1055-67.

6. Moskalev AA, Shaposhnikov MV, Plyusnina EN, Zhavoronkov A, Budovsky A, Yanai $\mathrm{H}$, Fraifeld VE. The role of DNA damage and repair in aging through the prism of Koch-like criteria. Ageing Res Rev. 2013;12(2):661-84.

7. Stuart GR, Oda Y, de Boer JG, Glickman BW. Mutation frequency and specificity with age in liver, bladder and brain of lacl transgenic mice. Genetics. 2000;154(3):1291-300.

8. Ono $T$, Ikehata $H$, Pithani VP, Uehara $Y$, Chen $Y$, Kinouchi $Y$, Shimosegawa T, Hosoi Y. Spontaneous mutations in digestive tract of old mice show tissuespecific patterns of genomic instability. Cancer Res. 2004;64(19):6919-23.

9. Cabelof DC, Yanamadala S, Raffoul JJ, Guo Z, Soofi A, Heydari AR. Caloric restriction promotes genomic stability by induction of base excision repair and reversal of its age-related decline. DNA Repair (Amst). 2003;2(3):295-307.
10. Kaneko T, Tahara S, Tanno M, Taguchi T. Age-related changes in the induction of DNA polymerases in rat liver by gamma-ray irradiation. Mech Ageing Dev. 2002;123(11):1521-8.

11. Atamna $\mathrm{H}$, Cheung I, Ames BN. A method for detecting abasic sites in living cells: age-dependent changes in base excision repair. Proc Natl Acad Sci USA. 2000;97(2):686-91.

12. Seluanov A, Mittelman D, Pereira-Smith OM, Wilson JH, Gorbunova V. DNA end joining becomes less efficient and more error-prone during cellular senescence. Proc Natl Acad Sci USA. 2004;101(20):7624-9.

13. Mao Z, Tian X, Van Meter M, Ke Z, Gorbunova V, Seluanov A. Sirtuin 6 (SIRT6) rescues the decline of homologous recombination repair during replicative senescence. Proc Natl Acad Sci USA. 2012;109(29):11800-5.

14. Vaidya A, Mao Z, Tian X, Spencer B, Seluanov A, Gorbunova V. Knock-in reporter mice demonstrate that DNA repair by non-homologous end joining declines with age. PLoS Genet. 2014;10(7):e1004511.

15. Feng Z, Hu W, Teresky AK, Hernando E, Cordon-Cardo C, Levine AJ. Declining p53 function in the aging process: a possible mechanism for the increased tumor incidence in older populations. Proc Natl Acad Sci USA. 2007:104(42):16633-8.

16. Panda S, Isbatan A, Adami GR. Modification of the ATM/ATR directed DNA damage response state with aging and long after hepatocyte senescence induction in vivo. Mech Ageing Dev. 2008;129(6):332-40

17. Vogel H, Lim DS, Karsenty G, Finegold M, Hasty P. Deletion of Ku86 causes early onset of senescence in mice. Proc Natl Acad Sci USA. 1999;96(19):10770-5.

18. Li H, Vogel H, Holcomb VB, Gu Y, Hasty P. Deletion of Ku70, Ku80, or both causes early aging without substantially increased cancer. Mol Cell Biol. 2007:27(23):8205-14.

19. Mostoslavsky R, Chua KF, Lombard DB, Pang WW, Fischer MR, Gellon L, Liu P. Mostoslavsky G, Franco S, Murphy MM, et al. Genomic instability and aging-like phenotype in the absence of mammalian SIRT6. Cell. 2006:124(2):315-29.

20. Burtner CR, Kennedy BK. Progeria syndromes and ageing: what is the connection? Nat Rev Mol Cell Biol. 2010;11(8):567-78.

21. Cao K, Blair CD, Faddah DA, Kieckhaefer JE, Olive M, Erdos MR, Nabel EG, Collins FS. Progerin and telomere dysfunction collaborate to trigger cellular senescence in normal human fibroblasts. J Clin Invest. 2011;121(7):2833-44.

22. Hsieh JC, Van Den Berg D, Kang H, Hsieh CL, Lieber MR. Large chromosome deletions, duplications, and gene conversion events accumulate with age in normal human colon crypts. Aging Cell. 2013;12(2):269-79.

23. Jacobs KB, Yeager M, Zhou W, Wacholder S, Wang Z, Rodriguez-Santiago B, Hutchinson A, Deng X, Liu C, Horner MJ, et al. Detectable clonal mosaicism and its relationship to aging and cancer. Nat Genet. 2012;44(6):651-8.

24. Laurie CC, Laurie CA, Rice $K$, Doheny KF, Zelnick LR, McHugh $C P$, Ling $H$, Hetrick KN, Pugh EW, Amos C, et al. Detectable clonal mosaicism from birth to old age and its relationship to cancer. Nat Genet. 2012;44(6):642-50.

25. Machiela MJ, Zhou W, Sampson JN, Dean MC, Jacobs KB, Black A, Brinton LA, Chang IS, Chen C, Chen K, et al. Characterization of large structural genetic mosaicism in human autosomes. Am J Hum Genet. 2015;96(3):487-97

26. Lodato MA, Woodworth MB, Lee S, Evrony GD, Mehta BK, Karger A Chittenden TW, D'Gama AM, Cai X, Luquette L, et al. Somatic mutation in single human neurons tracks developmental and transcriptional history. Science. 2015;350(6256):94-8.

27. Madia F, Wei M, Yuan V, Hu J, Gattazzo C, Pham P, Goodman MF, Longo VD. Oncogene homologue Sch9 promotes age-dependent mutations by a superoxide and Rev1/Polzeta-dependent mechanism. J Cell Biol. 2009; 186(4):509-23.

28. Rudolph KL, Chang S, Lee HW, Blasco M, Gottlieb GJ, Greider C, DePinho RA Longevity, stress response, and cancer in aging telomerase-deficient mice. Cell. 1999;96(5):701-12.

29. Tomás-Loba A, Flores I, Fernández-Marcos PJ, Cayuela ML, Maraver A, Tejera A, Borrás C, Matheu A, Klatt P, Flores JM, et al. Telomerase reverse transcriptase delays aging in cancer-resistant mice. Cell. 2008;135(4):609-22.

30. Armanios M, Alder JK, Parry EM, Karim B, Strong MA, Greider CW. Short telomeres are sufficient to cause the degenerative defects associated with aging. Am J Hum Genet. 2009;85(6):823-32.

31. Bernardes de Jesus B, Schneeberger K, Vera E, Tejera A, Harley CB, Blasco MA. The telomerase activator TA-65 elongates short telomeres and increases health span of adult/old mice without increasing cancer incidence. Aging Cell. 2011;10(4):604-21. 
32. Bernardes De Jesus B, Vera E, Schneeberger K, Tejera AM, Ayuso E, Bosch F, Blasco MA. Telomerase gene therapy in adult and old mice delays aging and increases longevity without increasing cancer. EMBO Mol Med. 2012;4(8):691-704.

33. Longo VD, Shadel GS, Kaeberlein M, Kennedy B. Replicative and chronological aging in Saccharomyces cerevisiae. Cell Metab. 2012;16(1):18-31.

34. Madia F, Gattazzo C, Fabrizio P, Longo VD. A simple model system for agedependent DNA damage and cancer. Mech Ageing Dev. 2007;128(1):45-9.

35. Maxwell PH, Burhans WC, Curcio MJ. Retrotransposition is associated with genome instability during chronological aging. Proc Natl Acad Sci U S A. 2011;108(51):20376-81.

36. McMurray MA, Gottschling DE. An age-induced switch to a hyperrecombinational state. Science. 2003;301(5641):1908-11.

37. Lindstrom DL, Leverich CK, Henderson KA, Gottschling DE. Replicative age induces mitotic recombination in the ribosomal RNA gene cluster of Saccharomyces cerevisiae. PLoS Genet. 2011;7(3):e1002015.

38. Patterson MN, Scannapieco AE, Au PH, Dorsey S, Royer CA, Maxwell PH. Preferential retrotransposition in aging yeast mother cells is correlated with increased genome instability. DNA Repair (Amst). 2015;34:18-27.

39. Hu Z, Chen K, Xia Z, Chavez M, Pal S, Seol JH, Chen CC, Li W, Tyler JK. Nucleosome loss leads to global transcriptional up-regulation and genomic instability during yeast aging. Genes Dev. 2014;28(4):396-408.

40. Park PU, Defossez PA, Guarente L. Effects of mutations in DNA repair genes on formation of ribosomal DNA circles and life span in Saccharomyces cerevisiae. Mol Cell Biol. 1999;19(5):3848-56.

41. Hoopes LL, Budd M, Choe W, Weitao T, Campbell JL. Mutations in DNA replication genes reduce yeast life span. Mol Cell Biol. 2002;22(12):4136-46.

42. Fabrizio P, Hoon S, Shamalnasab M, Galbani A, Wei M, Giaever G, Nislow C, Longo VD. Genome-wide screen in Saccharomyces cerevisiae identifies vacuolar protein sorting, autophagy, biosynthetic, and tRNA methylation genes involved in life span regulation. PLoS Genet. 2010;6(7):e1001024.

43. Matecic M, Smith DL, Pan X, Maqani N, Bekiranov S, Boeke JD, Smith JS. A microarray-based genetic screen for yeast chronological aging factors. PLoS Genet. 2010;6(4):e1000921.

44. Smith DL, McClure JM, Matecic M, Smith JS. Calorie restriction extends the chronological lifespan of Saccharomyces cerevisiae independently of the Sirtuins. Aging Cell. 2007;6(5):649-62.

45. Burtner CR, Murakami CJ, Kennedy BK, Kaeberlein M. A molecular mechanism of chronological aging in yeast. Cell Cycle. 2009;8(8):1256-70.

46. Weinberger M, Mesquita A, Caroll T, Marks L, Yang H, Zhang Z, Ludovico $P$, Burhans WC. Growth signaling promotes chronological aging in budding yeast by inducing superoxide anions that inhibit quiescence. Aging (Albany NY). 2010;2(10):709-26.

47. Lin SJ, Defossez PA, Guarente L. Requirement of NAD and SIR2 for life-span extension by calorie restriction in Saccharomyces cerevisiae. Science. 2000;289(5487):2126-8

48. Ringvoll J, Uldal L, Roed MA, Reite K, Baynton K, Klungland A, Eide L. Mutations in the RAD27 and SGS1 genes differentially affect the chronological and replicative lifespan of yeast cells growing on glucose and glycerol. FEMS Yeast Res. 2007;7(6):848-59.

49. Weinberger M, Feng L, Paul A, Smith DL, Hontz RD, Smith JS, Vujcic M, Singh KK, Huberman JA, Burhans WC. DNA replication stress is a determinant of chronological lifespan in budding yeast. PLoS One. 2007;2(8):e748

50. Weinberger M, Sampaio-Marques B, Ludovico P, Burhans WC. DNA replication stress-induced loss of reproductive capacity in S. cerevisiae and its inhibition by caloric restriction. Cell Cycle. 2013;12(8):1189-200.

51. Amberg DC, Burke DJ, Strathern JN. Methods in Yeast Genetics: A Cold Spring Harbor Laboratory Course Manual. 2005th ed. Cold Spring Harbor: Cold Spring Harbor Laboratory Press; 2005.

52. Conte D, Barber E, Banerjee M, Garfinkel DJ, Curcio MJ. Posttranslational regulation of Ty1 retrotransposition by mitogen-activated protein kinase Fus3. Mol Cell Biol. 1998;18(5):2502-13.

53. Sikorski RS, Hieter P. A system of shuttle vectors and yeast host strains designed for efficient manipulation of DNA in Saccharomyces cerevisiae. Genetics. 1989;122(1):19-27.

54. Foster PL. Methods for determining spontaneous mutation rates. Methods Enzymol. 2006;409:195-213.

55. Whelan WL, Gocke E, Manney TR. The CAN1 locus of Saccharomyces cerevisiae: fine-structure analysis and forward mutation rates. Genetics. 1979;91(1):35-51.
56. Boeke JD, LaCroute F, Fink GR. A positive selection for mutants lacking orotidine-5'-phosphate decarboxylase activity in yeast: 5-fluoro-orotic acid resistance. Mol Gen Genet. 1984;197(2):345-6.

57. Curcio MJ, Garfinkel DJ. Single-step selection for Ty1 element retrotransposition. Proc Natl Acad Sci U S A. 1991;88(3):936-40.

58. Hall BM, Ma CX, Liang P, Singh KK. Fluctuation analysis CalculatOR: a web tool for the determination of mutation rate using Luria-Delbruck fluctuation analysis. Bioinformatics. 2009;25(12):1564-5.

59. Paquin CE, Williamson VM. Temperature effects on the rate of ty transposition. Science. 1984;226(4670):53-5.

60. Lawler JF, Haeusser DP, Dull A, Boeke JD, Keeney JB. Ty1 defect in proteolysis at high temperature. J Virol. 2002;76(9):4233-40.

61. Barros $M H$, Bandy B, Tahara EB, Kowaltowski AJ. Higher respiratory activity decreases mitochondrial reactive oxygen release and increases life span in Saccharomyces cerevisiae. J Biol Chem. 2004:279(48):49883-8.

62. Murakami CJ, Burtner CR, Kennedy BK, Kaeberlein M. A method for highthroughput quantitative analysis of yeast chronological life span. J Gerontol A Biol Sci Med Sci. 2008;63(2):113-21.

63. Bonawitz ND, Chatenay-Lapointe M, Pan Y, Shadel GS. Reduced TOR signaling extends chronological life span via increased respiration and upregulation of mitochondrial gene expression. Cell Metab. 2007;5(4):265-77.

64. Pan Y, Schroeder EA, Ocampo A, Barrientos A, Shadel GS. Regulation of yeast chronological life span by TORC1 via adaptive mitochondrial ROS signaling. Cell Metab. 2011;13(6):668-78.

65. VanHoute D, Maxwell PH. Extension of Saccharomyces paradoxus chronological lifespan by retrotransposons in certain media conditions is associated with changes in reactive oxygen species. Genetics. 2014;198(2):531-45.

66. Engel SR, Dietrich FS, Fisk DG, Binkley G, Balakrishnan R, Costanzo MC, Dwight SS, Hitz BC, Karra K, Nash RS, et al. The reference genome sequence of Saccharomyces cerevisiae: then and now. G3 (Bethesda). 2014;4(3):389-98.

67. Carr AM, Lambert S: Replication Stress-Induced Genome Instability: The Dark Side of Replication Maintenance by Homologous Recombination. J Mol Biol. 2013; 425(23):4733-44.

68. Burhans W, Weinberger M. Acetic acid effects on aging in budding yeast: are they relevant to aging in higher eukaryotes? Cell Cycle. 2009:8(14):2300-2.

69. Krogh BO, Symington LS. Recombination proteins in yeast. Annu Rev Genet. 2004:38:233-71.

70. Kunz BA, Peters MG, Kohalmi SE, Armstrong JD, Glattke M, Badiani K. Disruption of the RAD52 gene alters the spectrum of spontaneous SUP4-o mutations in Saccharomyces cerevisiae. Genetics. 1989;122(3):535-42.

71. Vijg J. Somatic mutations, genome mosaicism, cancer and aging. Curr Opin Genet Dev. 2014;26:141-9.

72. Kaya A, Lobanov AV, Gladyshev VN. Evidence that mutation accumulation does not cause aging in Saccharomyces cerevisiae. Aging Cell. 2015;14(3):366-71.

73. Orozco H, Matallana E, Aranda A. Two-carbon metabolites, polyphenols and vitamins influence yeast chronological life span in winemaking conditions. Microb Cell Fact. 2012;11:104

74. Wang J, Geesman GJ, Hostikka SL, Atallah M, Blackwell B, Lee E, Cook PJ Pasaniuc B, Shariat G, Halperin E, et al. Inhibition of activated pericentromeric SINE/Alu repeat transcription in senescent human adult stem cells reinstates self-renewal. Cell Cycle. 2011;10(17):3016-30.

75. Dennis S, Sheth U, Feldman JL, English KA, Priess JR. C. elegans germ cells show temperature and age-dependent expression of Cer1, a Gypsy/Ty3related retrotransposon. PLoS Pathog. 2012;8(3):e1002591.

76. De Cecco M, Criscione SW, Peckham EJ, Hillenmeyer S, Hamm EA, Manivannan J, Peterson AL, Kreiling JA, Neretti N, Sedivy JM. Genomes of replicatively senescent cells undergo global epigenetic changes leading to gene silencing and activation of transposable elements. Aging Cell. 2013;12(2):247-56

77. De Cecco M, Criscione SW, Peterson AL, Neretti N, Sedivy JM, Kreiling JA. Transposable elements become active and mobile in the genomes of aging mammalian somatic tissues. Aging (Albany NY). 2013;5(12):867-83.

78. Li W, Prazak L, Chatterjee N, Grüninger S, Krug L, Theodorou D, Dubnau J. Activation of transposable elements during aging and neuronal decline in Drosophila. Nat Neurosci. 2013;16(5):529-31.

79. Pastink A, Eeken JC, Lohman PH. Genomic integrity and the repair of double-strand DNA breaks. Mutat Res. 2001;480-481:37-50.

80. Myung K, Datta A, Chen C, Kolodner RD. SGS1, the Saccharomyces cerevisiae homologue of BLM and WRN, suppresses genome instability and homeologous recombination. Nat Genet. 2001;27(1):113-6. 
81. Spell RM, Jinks-Robertson S. Examination of the roles of Sgs1 and Srs2 helicases in the enforcement of recombination fidelity in Saccharomyces cerevisiae. Genetics. 2004;168(4):1855-65.

82. Madia F, Gattazzo C, Wei M, Fabrizio P, Burhans WC, Weinberger M, Galbani A, Smith JR, Nguyen C, Huey S, et al. Longevity mutation in SCH9 prevents recombination errors and premature genomic instability in a Werner/Bloom model system. J Cell Biol. 2008;180(1):67-81.

83. Sinclair DA, Mills K, Guarente L. Accelerated aging and nucleolar fragmentation in yeast sgs1 mutants. Science. 1997;277(5330):1313-6.

84. Flach J, Bakker ST, Mohrin M, Conroy PC, Pietras EM, Reynaud D, Alvarez S, Diolaiti ME, Ugarte F, Forsberg EC, et al. Replication stress is a potent driver of functional decline in ageing haematopoietic stem cells. Nature. 2014;512(7513):198-202.

85. Shen J, Loeb LA. Unwinding the molecular basis of the Werner syndrome. Mech Ageing Dev. 2001;122(9):921-44.

86. Kamath-Loeb AS, Shen JC, Schmitt MW, Loeb LA. The Werner syndrome exonuclease facilitates DNA degradation and high fidelity DNA polymerization by human DNA polymerase $\delta$. J Biol Chem. 2012:287(15):12480-90

87. Lessel D, Vaz B, Halder S, Lockhart PJ, Marinovic-Terzic I, Lopez-Mosqueda J, Philipp M, Sim JC, Smith KR, Oehler J, et al. Mutations in SPRTN cause early onset hepatocellular carcinoma, genomic instability and progeroid features. Nat Genet. 2014;46(11):1239-44.

88. Hills SA, Diffley JF. DNA replication and oncogene-induced replicative stress. Curr Biol. 2014;24(10):R435-444.

\section{Submit your next manuscript to BioMed Central and we will help you at every step:}

- We accept pre-submission inquiries

- Our selector tool helps you to find the most relevant journal

- We provide round the clock customer support

- Convenient online submission

- Thorough peer review

- Inclusion in PubMed and all major indexing services

- Maximum visibility for your research

Submit your manuscript at www.biomedcentral.com/submit 